\title{
High field electrical behaviour in lithium-phospho-vanadate glass system
}

\author{
C NARAYANA REDDY ${ }^{\dagger}$, S ASOKAN ${ }^{\dagger \dagger}$ and R V ANAVEKAR* \\ Department of Physics, Bangalore University, Bangalore 560 056, India \\ ${ }^{\dagger}$ Department of Physics, P.E.S. College, Bangalore 560 050, India \\ ${ }^{\dagger \dagger}$ Department of Instrumentation, Indian Institute of Science, Bangalore 560 012, India
}

MS received 9 June 2005

\begin{abstract}
The high field electrical switching behaviour of lithium-phospho-vanadate glasses has been studied by determining the current-voltage characteristics. The investigated glasses exhibit temperature, thickness and composition dependent trends. At low current, the $I-V$ characteristics obey Ohm's law followed by a negative resistance region where the bulk behaviour dominates and at higher values of current the sample goes to a low resistance state. The studied glasses exhibit memory type switching. It is suggested that electrical switching is due to the formation of conducting channels that are due to electronic origin while thermal effects dominate once the channels are formed resulting in crystallization.
\end{abstract}

Keywords. High field electrical behaviour; lithium-phospho-vanadate glass system.

\section{Introduction}

High field electrical switching behaviour is one of the fascinating properties in oxide glasses, since it exhibits reversible threshold and irreversible memory states. Several investigations have been initiated to study switching in glasses containing $\mathrm{V}_{2} \mathrm{O}_{5}, \mathrm{MoO}_{3}, \mathrm{Fe}_{2} \mathrm{O}_{3}$ etc with glass formers such as $\mathrm{P}_{2} \mathrm{O}_{5}, \mathrm{~B}_{2} \mathrm{O}_{3}, \mathrm{TeO}_{2}$ etc to understand the electrical switching behaviour as a function of temperature, material thickness and compositions (Mansingh and Dhawan 1983; Vaidyanathan et al 1995a; Panchal and Kanchan 1999). It has been well established that electrical switching may be either thermal, electro-thermal or purely electronic (Henish et al 1970; Boer 1971; Motani et al 1992). A number of amorphous semiconductors and FICs are known to exhibit negative resistance or 'switching' behaviour at high voltages (Chakravorthy and Mathews 1989; Vaidhyanathan et al 1995b). The phenomenon of negative resistance and switching in glasses are of interest because they can be non-destructive, whereas the electric breakdown of insulators at high voltages is destructive. Switching phenomena in amorphous materials find applications in information storage and power control devices (Asokan 2001). Lithium based systems fulfill voltage and energy density requirements and it has also been reported that electronic conductive glasses can be used as cathode materials (e.g. $\mathrm{V}_{2} \mathrm{O}_{5}-$ $\mathrm{P}_{2} \mathrm{O}_{5}$ or $\mathrm{V}_{2} \mathrm{O}_{5}-\mathrm{TeO}_{2}$ ) (Paguier et al 1983). In the present report, we have attempted to explain the switching pheno-

\footnotetext{
*Author for correspondence (anavekar_271@yahoo.co.in)
}

mena on the basis of structural changes occurring due to the addition of modifier oxide $\left(\mathrm{Li}_{2} \mathrm{O}\right)$.

\section{Experimental}

Glasses having a general formula, $x \mathrm{Li}_{2} \mathrm{O}-10 \mathrm{P}_{2} \mathrm{O}_{5}-(90-x)$ $\mathrm{V}_{2} \mathrm{O}_{5}$ (where $x=1 \cdot 5,2 \cdot 5,5,10,15$ and $20 \mathrm{~mol} \%$ ), were prepared using analar grade lithium carbonate $\left(\mathrm{Li}_{2} \mathrm{CO}_{3}\right)$, vanadium pentoxide $\left(\mathrm{V}_{2} \mathrm{O}_{5}\right)$ and ammonium dihydrogen orthophosphate $\left(\mathrm{NH}_{4} \mathrm{H}_{2} \mathrm{PO}_{4}\right)$ as starting materials. An appropriate quantity of weighed chemicals were mixed and thoroughly ground to homogenize the mixture. Depending upon the composition, the mixtures were melted at $900-1000^{\circ} \mathrm{C}$ for about $30 \mathrm{~min}$ to ensure homogeneity and then quenched between copper blocks. The glasses were annealed for $1 \mathrm{~h}$ at $200^{\circ} \mathrm{C}$ to remove thermal strains that could have developed during quenching. The prepared samples were crushed in a mortar to a fine powder and tested for amorphous nature of glass using a powder diffractometer (Rigaku DMAX-1C). The X-ray diffractogram showed no sharp peaks indicating that the samples were amorphous in nature.

The high field behaviour of these glasses were studied using a custom built PC based system (Chatterjee et al 1994). Samples were mechanically polished using carborundum powder to a thickness of $0 \cdot 15-0 \cdot 3 \mathrm{~mm}$. The sample, whose switching behaviour is to be studied, was mounted in a spring-loaded cell between a point contact top electrode (cathode) and a flat plate bottom electrode made of brass. A programmable, constant direct current 
Table 1. Composition, thickness and threshold voltages.

\begin{tabular}{|c|c|c|c|c|c|c|}
\hline $\begin{array}{l}\mathrm{Li}_{2} \mathrm{O} \\
(\mathrm{mol} \%)\end{array}$ & $\begin{array}{c}\mathrm{P}_{2} \mathrm{O}_{5} \\
(\mathrm{~mol} \%)\end{array}$ & $\begin{array}{c}\mathrm{V}_{2} \mathrm{O}_{5} \\
(\mathrm{~mol} \%)\end{array}$ & $\begin{array}{c}\text { Threshold } \\
\text { voltage at } \\
d=0 \cdot 15 \mathrm{~mm} \\
\text { (V) }\end{array}$ & $\begin{array}{c}\text { Threshold } \\
\text { voltage at } \\
d=0.20 \mathrm{~mm} \\
\text { (V) }\end{array}$ & $\begin{array}{c}\text { Threshold } \\
\text { voltage at } \\
d=0.25 \mathrm{~mm} \\
\text { (V) }\end{array}$ & $\begin{array}{c}\text { Threshold } \\
\text { voltage at } \\
d=0.30 \mathrm{~mm} \\
\text { (V) }\end{array}$ \\
\hline $1 \cdot 5$ & 10 & 88.5 & 161 & 193 & 230 & 270 \\
\hline 5 & 10 & 85 & 227 & 257 & 273 & 221 \\
\hline 10 & 10 & 80 & 293 & 333 & 356 & 391 \\
\hline 15 & 10 & 75 & $348 \cdot 5$ & 381 & $407 \cdot 5$ & 444 \\
\hline 20 & 10 & 70 & $409 \cdot 5$ & $441 \cdot 5$ & $460 \cdot 5$ & 489 \\
\hline
\end{tabular}
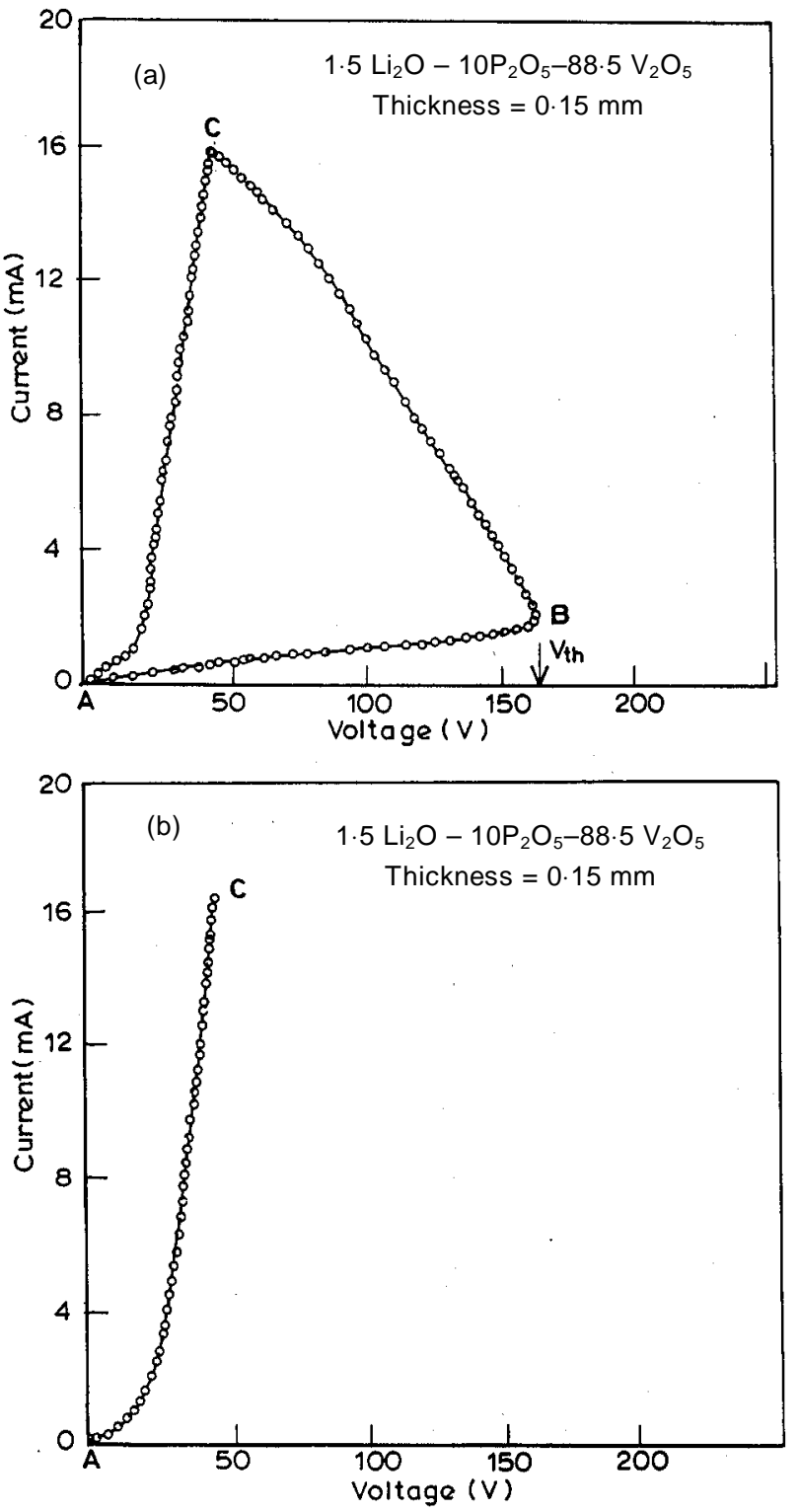

Figure 1. (a) $I-V$ characteristics at room temperature and (b) $I-V$ characteristics of the re-switched sample.

(0-50 mA) was passed through the sample and the voltage developed across was measured. The sample holder was kept in a temperature-controlled chamber to study the temperature effects on the sample.

\section{Results and discussion}

Electrical switching behaviour of $\mathrm{Li}_{2} \mathrm{O}-\mathrm{P}_{2} \mathrm{O}_{5}-\mathrm{V}_{2} \mathrm{O}_{5}$ glass system has been carried out over a wide range of composition, temperature and thickness. The threshold voltages are listed in table 1. Figure 1(a) shows typical $I-V$ characteristics of a glass with $88.5 \mathrm{~mol} \%$ of $\mathrm{V}_{2} \mathrm{O}_{5}$ (thickness of the sample kept at $0.2 \mathrm{~mm}$ ). It is seen from figure 1(a) that the voltage increases with current initially, at threshold current, $I_{\text {th }}$ (corresponding to a threshold voltage, $V_{\text {th }}$ ), the voltage starts decreasing with increasing current, passing through a negative resistance zone, to a low resistance state. In figure $1(\mathrm{a}), \mathrm{AB}$ indicates ohmic region where the current is very small. This indicates that the OFF state is established. BC indicates the negative resistance region, which represents the transition from OFF state to ON state. This transition is attributed to the formation of localized conductive zones across the sample and is referred to as 'differential negative resistance zone' (Mansingh and Dhawan 1983) and CA indicates the switched region, which illustrates the conductive $\mathrm{ON}$ state of the sample. It is clear from the $I-V$ cycles that, after reaching $V_{\text {th }}$ an irreversible state having conductivity level more than 6 orders of magnitude higher is obtained. In samples exhibiting current controlled negative resistance (CCNR) behaviour with memory, once set, the low resistance state is retained (Chatterjee et al 1994). Any subsequent $I-V$ cycles exhibit only the high conducting region, CA. When the experiment is repeated on the switched sample the shape of the graph is as shown in figure 1(b), indicating that the sample once switched, remains in the ON state (CA) which is a characteristic of memory switching.

The temperature dependence of threshold voltage $\left(V_{\mathrm{th}}\right)$ has been studied over a temperature range 300-333 K and the values of $V_{\text {th }}$ are listed in table 2 . The variation of threshold voltage with temperature is shown in figure 2. The threshold voltage is found to decrease with increase of temperature. The observed variation of threshold voltage is similar to those reported in the literature (Mansingh and Dhawan 1983; Chatterjee et al 1994). The thickness dependence of $I-V$ characteristics has been carried out and 
figure 3 shows the variation of $V_{\text {th }}$ with sample thickness. As can be seen from figure 3 , the $V_{\text {th }}$ increases linearly with the sample thickness. Glasses of thickness $>0.4 \mathrm{~mm}$ did not show any switching behaviour. Over the entire composition range studied the glasses of varying thicknesses $(0 \cdot 15-0 \cdot 3 \mathrm{~mm})$ exhibit memory type of switching.

As explained in the literature the switching process is due to the formation of crystalline conducting channels between the electrodes at $V_{\mathrm{th}}$, giving rise to low resistance state. The decrease in $V_{\text {th }}$ with increase in temperature supports the idea that thermally generated conducting filaments are responsible for switching. As temperature increases, the molecular rearrangement becomes easier for the formation of localized conductive zones in the glass sample. The irreversible phenomenon has been attributed to the formation of a conducting filament in the switched region, which is understandably facilitated at higher temperature (Gohar et al 1997). Further, the thickness dependence of

Table 2. Switching voltages at different temperatures.

\begin{tabular}{lc}
\hline Temperature (K) & Threshold voltage (V) \\
\hline 300 & 381 \\
313 & 323 \\
323 & 267 \\
333 & 204 \\
\hline
\end{tabular}

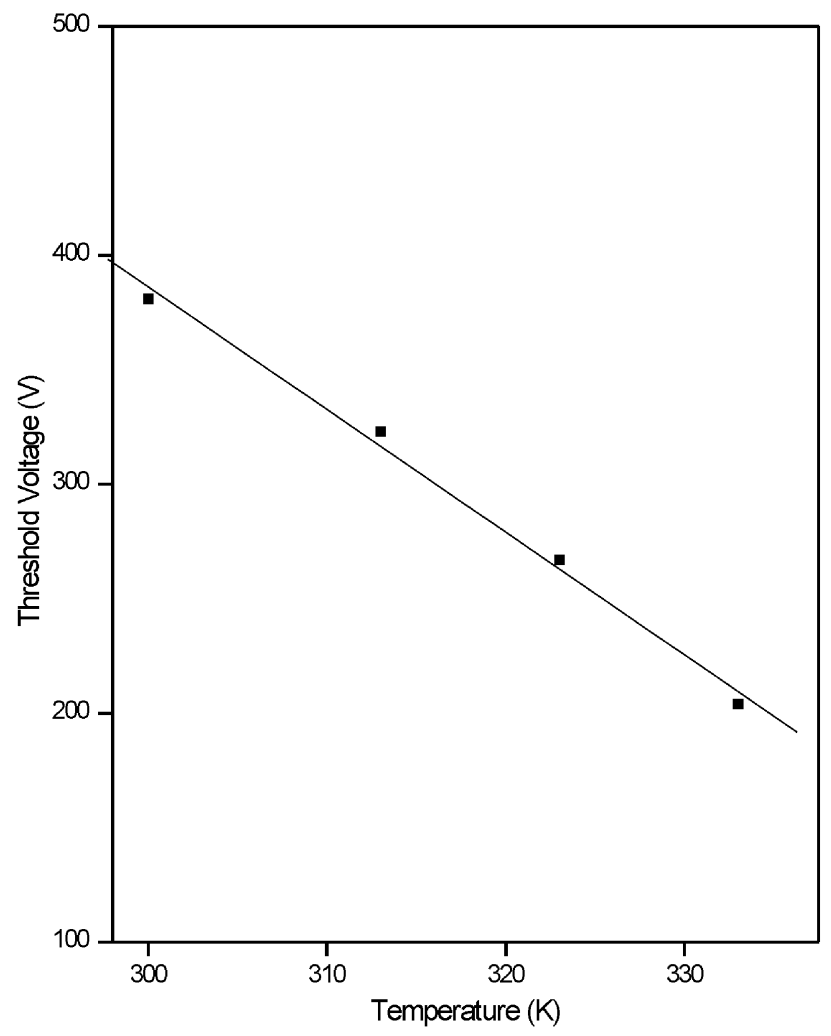

Figure 2. Variation of threshold voltage with temperature. threshold voltage clearly reveals that switching in these glasses is a bulk effect.

To study the effect of modifier oxide $\left(\mathrm{Li}_{2} \mathrm{O}\right)$ on switching behaviour, the experiments were performed by varying the modifier oxide concentration from 1.5-20 mol\%. The threshold voltages lie in the range of 161-489 V. All the glasses exhibit switching behaviour at room temperature, similar to those glasses containing transition metal oxides such as barium-vanadate (Gohar et al 1997), bismuthvanadate (Ghosh 1988) and calcium-phospho-vanadate glasses containing iron etc (Hirashima 1987).

Figure 4 shows the variation of threshold voltage with $\mathrm{V}_{2} \mathrm{O}_{5}$ mol\%. As can be seen from figure 4 the threshold voltage decreases linearly with increase in concentration of $\mathrm{V}_{2} \mathrm{O}_{5}$, for a given thickness (threshold voltage increases with increase of $\mathrm{Li}_{2} \mathrm{O}$ ). The composition dependence of electrical switching could be probably due to the structural origin. In glasses containing $\mathrm{V}_{2} \mathrm{O}_{5}$, the conductivity has been known to increase with increase of $\mathrm{V}_{2} \mathrm{O}_{5}$ concentration and this can be attributed to the decrease in $V-V$ distance as well as increase in redox-ratio $\left[V^{4+} /\left(V^{4+}+V^{5+}\right)\right]$. We, therefore, tried to correlate this aspect by considering the various structural groups likely to form in these glasses. Here $\mathrm{P}_{2} \mathrm{O}_{5}$ and $\mathrm{V}_{2} \mathrm{O}_{5}$ behave as glass formers, while $\mathrm{Li}_{2} \mathrm{O}$ is a network modifier. Phospho-vanadate glass is a continuous network of $\left[\mathrm{POO}_{3 / 2}\right]^{0}$ and $\left[\mathrm{VOO}_{3 / 2}\right]^{0}$ groups and the addition of $\mathrm{Li}_{2} \mathrm{O}$ will modify these groups into $\left[\mathrm{POO}_{2 / 2} \mathrm{O}\right]^{-}$ and $\left[\mathrm{VOO}_{2 / 2} \mathrm{O}\right]^{-}$, respectively. The preferential modifica-

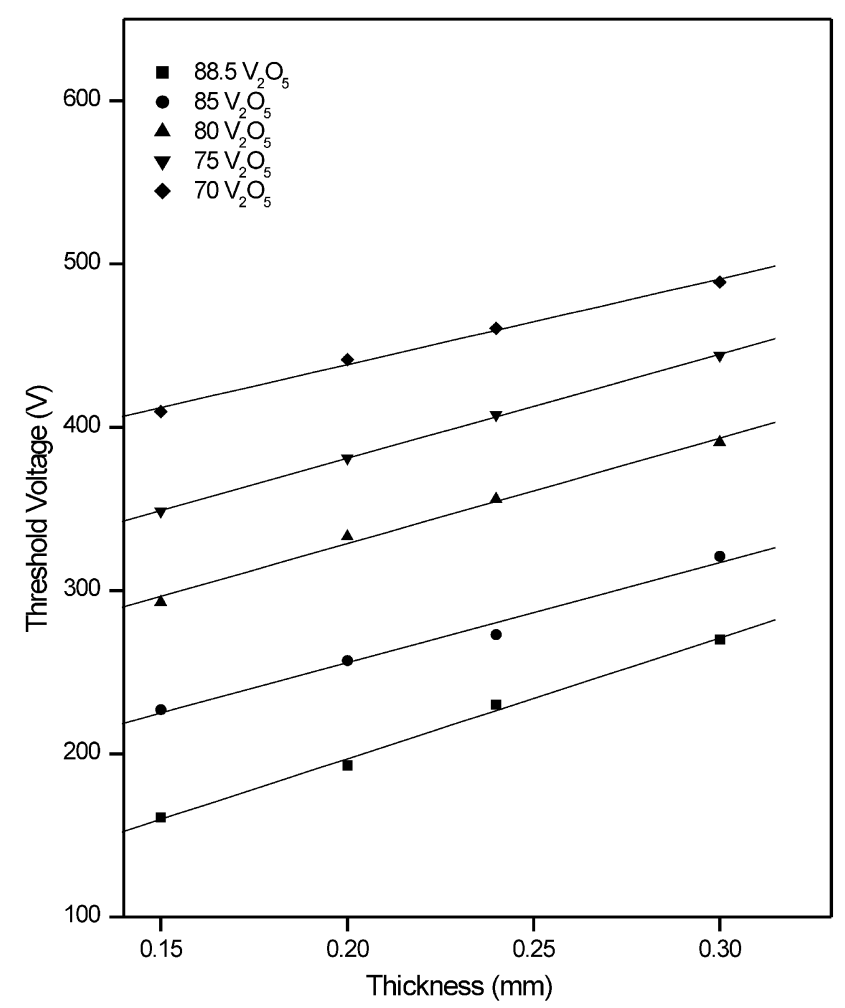

Figure 3. Variation of threshold voltage with thickness. 
Table 3. Glass composition and network modification.

\begin{tabular}{|c|c|c|c|}
\hline \multicolumn{3}{|c|}{ Glass composition (mol\%) } & \multirow[b]{2}{*}{ Network modification } \\
\hline $\mathrm{Li}_{2} \mathrm{O}$ & $\mathrm{P}_{2} \mathrm{O}_{5}$ & $\mathrm{~V}_{2} \mathrm{O}_{5}$ & \\
\hline $1 \cdot 5$ & 10 & $88 \cdot 5$ & $3\left[\mathrm{POO}_{2 / 2} \mathrm{O}\right]^{-}, 17\left[\mathrm{POO}_{3 / 2}\right]^{0}, 177\left[\mathrm{VOO}_{3 / 2}\right]^{0}$ \\
\hline $2 \cdot 5$ & 10 & $87 \cdot 5$ & $5\left[\mathrm{POO}_{2 / 2} \mathrm{O}\right]^{-}, 15\left[\mathrm{POO}_{3 / 2}\right]^{0}, 175\left[\mathrm{VOO}_{3 / 2}\right]^{0}$ \\
\hline 5 & 10 & 85 & $10\left[\mathrm{POO}_{2 / 2} \mathrm{O}\right]^{-}, 10\left[\mathrm{POO}_{3 / 2}\right]^{0}, 170\left[\mathrm{VOO}_{3 / 2}\right]^{0}$ \\
\hline 10 & 10 & 80 & $20\left[\mathrm{POO}_{2 / 2} \mathrm{O}\right]^{-}, 160\left[\mathrm{VOO}_{3 / 2}\right]^{0}$ \\
\hline 20 & 10 & 70 & $20\left[\mathrm{POO}_{2 / 2} \mathrm{O}\right]^{-}, 20\left[\mathrm{VOO}_{2 / 2} \mathrm{O}\right]^{-}, 120\left[\mathrm{VOO}_{3 / 2}\right]^{0}$ \\
\hline
\end{tabular}

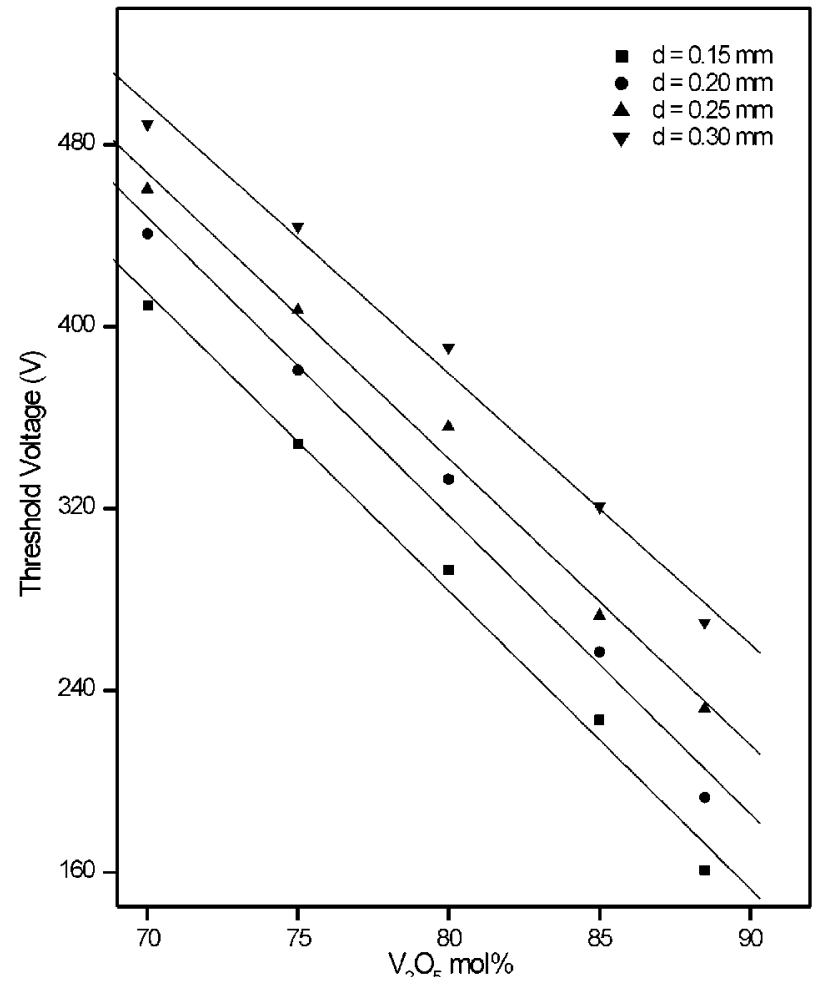

Figure 4. Variation of threshold voltage with $\mathrm{V}_{2} \mathrm{O}_{5}$ mol\%.

tion is decided by electronegativity, the one with higher electronegativity $\left[\mathrm{POO}_{3 / 2}\right]^{0}(\chi=3 \cdot 01)$ modifies first, then $\left[\mathrm{VOO}_{3 / 2}\right]^{0}(\chi=2.79)$ gets modified (Rao 2001). The electronegativities were calculated from Sanderson's principle. The glass composition and various groups due to network modification are listed in table 3 . It is clearly seen in table 3 that with increase of $\mathrm{Li}_{2} \mathrm{O}$ concentration there is a gradual decrease in $\left[\mathrm{VOO}_{3 / 2}\right]^{0}$ groups due to the formation of $\left[\mathrm{POO}_{2 / 2} \mathrm{O}\right]^{-}$and $\left[\mathrm{VOO}_{2 / 2} \mathrm{O}\right]^{-}$groups. As a consequence, this will give rise to an open structure and may cause decrease in $V-V$ distance and there will be reduction in the formation of localized conducting channels per unit area of the glass sample.

\section{Conclusions}

High field switching behaviour of lithium-phosphovanadate glasses exhibit composition, thickness and temperature dependent trends. The observed switching pheno- mena indicate that the process is a bulk effect. All the investigated glasses with $1 \cdot 5-20 \mathrm{~mol} \%$ of $\mathrm{Li}_{2} \mathrm{O}$ exhibit switching behaviour and it is of memory type. The switching voltages are seen to increase with the increase of $\mathrm{Li}_{2} \mathrm{O}$. Memory switching in these glasses is attributable to the formation of conducting channels. The temperature and thickness dependence indicate that switching is a bulk effect.

\section{Acknowledgements}

The authors are grateful to Prof. K J Rao, Solid State and Structural Chemistry Unit, Indian Institute of Science, Bangalore for encouragement and many helpful discussions. Financial support to one of the authors (RVA) from the UGC-DRS is gratefully acknowledged. One of the authors (CNR) thanks the UGC for providing a FIP fellowship.

\section{References}

Asokan S 2001 J. Optoelectronics Adv. Mater. 3753

Boer K W 1971 Phys. Status Solidi (a)4 571

Chakravorthy D and Mathews T 1989 J. Phys. D: Appl. Phys. 22149

Chatterjee R, Acharya K V, Asokan S and Titus S S K 1994 Rev. Sci. Instrum. $\mathbf{6 5} 2382$

Ghosh A 1988 J. Appl. Phys. 642652

Gohar I A, Moustafa Y M, Megahed A A and Mansour E 1997 Phys. Chem. Glasses 3837

Henish H K, Fagen E A, Ovshinsky S R and Fritzsche H 1970 J. Non-Cryst. Solids 4538

Hirashima Hiroshi, Watanabe Y and Yoshida T 1987 J. NonCryst. Solids $95 \& 98825$

Mansingh A and Dhawan V K 1983 Philos. Mag. B47 121

Motani R A, Levy M and Souquet J L 1992 J. Non-Cryst. Solids 149249

Paguier T, Fouletier M and Souquet J L 1983 Solid State Ionics 9/10 649

Panchal H R and Kanchan D K 1999 Tr. J. Phys. 23969

Rao K J 2001 Structural chemistry of glasses (Oxford, UK: Elsevier Science Ltd.)

Vaidhyanathan B, Rao K J, Prakash S, Murugavel S and Asokan S 1995a J. Appl. Phys. 781358

Vaidhyanathan B, Asokan S and Rao K J 1995b Bull. Mater. Sci. 18301 